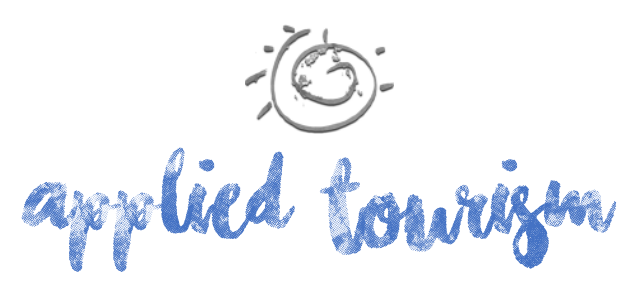

Volume 2, número 1,2017, p. 176-200

\title{
ECOLOGICAL FOOTPRINT METHOD- EFM: estudo dos indicadores da pegada ambiental do Eduardo Hotel de Foz do Iguaçu - PR
}

\author{
Eduardo Hack Neto \\ Doutor em Geografia (UFPR) \\ Universidade Federal do Paraná (UFPR) \\ professoreduardohack@gmail.com \\ Jhennifer dos Santos Nunes \\ Bacharel em Administração (UNIAMÉRICA) \\ jhennisn@gmail.com \\ Thaiana Lima de Oliveira \\ Bacharel em Adminstração (UNIAMÉRICA) \\ thaiana.lima@hotmail.com
}

Recebido: 17 de junho, 2016

Aprovado: 17 de novembro, 2016

\section{RESUMO}

Um número crescente de estudos busca avaliar impactos ambientais das indústrias e cidades. Todavia, ainda são raros os levantamentos que o setor turístico confere à pegada ambiental. Frente esta lacuna, objetiva-se especificamente com este estudo identificar EFM dos itens eletricidade, mobilidade, água, resíduos e uso do solo (desencadeadores) dos doze meses do ano 2013 de um hotel e verificar o Holiday EFM dos possíveis turistas do meiode hospedagem. O método delineado assume técnicas de pesquisa quantitativa com bases exploratórias. Os instrumentos utilizados foram documentos, planilhas virtuais e formulários de questões aplicados à demanda potencial da empresa, nos dois principais atrativos turísticos da cidade (Cataratas do Iguaçu e Itaipu Binacional). Os resultados demonstram que o consumo de água teve maior relevância em relação aos outros desencadeadores. Ainda que a compensação pode, de forma simples, seguir dicas de selos e cartilhas ambientais vigentes.

Palavras-chave: EcologicalFootprint Method. Holiday EFM. Indicadores. 


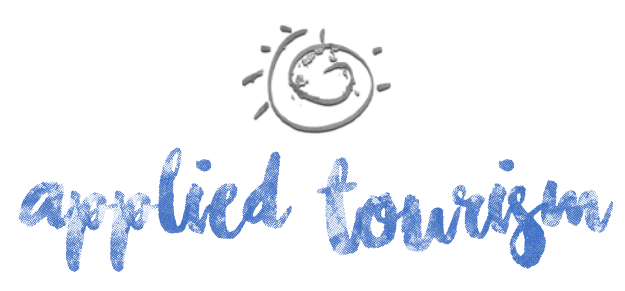

Volume 2, número 1,2017, p. 176-200

\section{INTRODUÇÃO}

Segundo o Embratur (2014) o Brasil ocupa o $6^{\circ}$ lugar no mundo em economia no turismo, visto que o país organizou a Copa do Mundo em 2014 e sediará as Olimpíadas em 2016. Neste contexto, o país recebeu cerca de 700 mil turistas estrangeiros (Folha de São Paulo, 2014), com lucro de US\$1,4 bilhões (Ministério do Turismo, 2014).

Nesse cenário competitivo destacam-se além das empresas, os destinos turísticos. Dentre os que evidenciam o turismo no Brasil ressalta-se Foz do Iguaçu, segunda cidade brasileira mais visitada por estrangeiros com intuito turístico (Abeoc, 2014). O destino é conhecido mundialmente pelos seus atrativos turísticos como as Cataratas do Iguaçu reconhecida pela fundação New 7 Wonders como uma das Sete Novas Maravilhas Naturais do Mundo e a Itaipu Binacional considerada uma das Sete Maravilhas do Mundo Moderno (Sebrae, 2014).

Segundo a Secretaria Municipal de Turismo (2014), a cidade tem o quarto maior parque hoteleiro do Brasil, que correspondem a 161 meios de hospedagens, desde pousadas e hotéis de categoria econômica até os padrões internacionais e os resorts, em um total de aproximadamente 22 mil leitos. Vale destacar desses 44,95\% se enquadram na categoria uma ou duas estrelas, e dentre esses encontra-se o empreendimento abordado neste artigo.

Considerando que o hotel se enquadra na categoria duas estrelas, percebe-se uma alta competitividade gerando uma disputa de hóspedes, muitas com foco nos preços, segundo os gestores. Frente a essa problemática, acredita-se que a implementação de alguns elementos oriundos de um Sistema de Gestão Ambiental possa ser um diferencial competitivo entre os meios de hospedagens da mesma categoria. Entretanto, somente um estudo acerca de seus indicadores e possibilidades compensatórias demonstraria a possibilidade da realização deste. Diante desta situação, procurou-se entender e aplicar os conceitos do EFM e do Holiday EFM no referido empreendimento. 


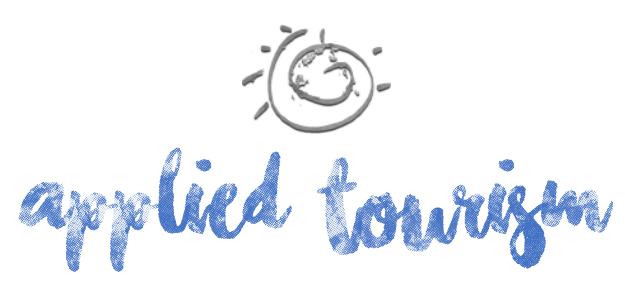

Volume 2, número 1,2017, p. 176-200

\section{ECOLOGICAL FOOTPRINT METHOD E HOLIDAY EFM}

Visto que o turismo é um setor que possui uma parcela no impacto ambiental deve-se pensar em uma medida para minimizar a consequência ambiental. Deste modo, o EFM é um procedimento que pode auxiliar nesse aspecto, cuja tradução para o português possui o significado literal Método da Pegada Ecológica.

De acordo com Parente (2007, p. 22) o "EFM nasceu com a finalidade de estimar os impactos no meio natural, mostrar a quantidade de área produtiva de terra e de água utilizada para fornecer os produtos para abastecer a população". A partir desse contexto criou-se um cálculo para identificar a pegada ecológica. Para Sebastião (2010, p. 30) "a pegada ecológica apresenta-se como um indicador de sustentabilidade ecológica voltada para a dimensão ambiental do desenvolvimento sustentável". Dessa forma, o cálculo é um critério para diagnosticar o impacto causado pelo homem.

Segundo Furtado, Hourneaux Junior \& Hrdlicka (2008, p. 2) "a pegada ecológica é expressa por um indicador métrico, caracterizado pelo número de hectares de terra/área bioprodutiva necessários para que sejam providos os recursos naturais renováveis que sustentam o padrão de consumo". Nesse aspecto, é um instrumento para contabilizar o impacto ambiental causado pelo ser humano.

De acordo com Wackernagel \& Ress (1996) apud Parente (2007, p. 24) o EFM "é uma ferramenta projetada com a finalidade de mensurar a sustentabilidade ambiental, focalizando as preocupações globais, a deterioração ecológica e as injustiças sociais". Em outras palavras, permite estabelecer, as relações de dependência entre o indivíduo, as suas atividades e os recursos naturais necessários para a realização das mesmas e para absorção dos resíduos gerados, assim permite-se estimar a quantidade em áreas terra (hag.), para sustentar a manutenção do sistema (Dias, 2007, apud Sebastião, 2010). 


\section{(2)

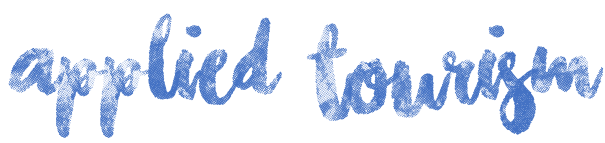

Volume 2, número 1,2017, p. 176-200

Para entender como funciona o método faz-se necessário compreender o padrão de consumo da população de cada região. Considerando que o consumo elevado interfere diretamente nos recursos naturais, origina-se este recurso com a proposta de identificação para apontar o impacto causado pelo homem.

Esta ferramenta é utilizada tanto para calcular o consumo do homem quanto de uma empresa, cidade, estado, país ou até mesmo em escala global. Para Parente (2007, p. 23), o EFM "é um mecanismo que proporciona condições aos tomadores de decisões em projetar as atividades visando minimizar os impactos decorrentes das atividades humanas contra o capital natural". Portanto, para calculá-la é necessário pensar em cinco indicadores de consumo que usam a maior quantidade dos recursos naturais tais como: alimentação (vegetais e carnes), habitação (área construída), transporte (público ou privado), bens de consumo (equipamento, roupas, papel e outros) e serviços (banco, hospedagem, restaurante entre outros) (Andrade, 2006; Sebastião, 2010; Parente, 2007).

Esses fatores são a base do cálculo da pegada ecológica. Percebe-se que as categorias citadas são calculadas em hectares de terra (Feitosa \& Gómez, 2013). A partir desse pressuposto a EFM torna-se um aliado para o turismo, pois o método mensura o quanto este consume em terra/área para suportar o padrão de consumo do turista. A partir desse contexto o turista é o ponto crucial para o empreendimento hoteleiro, pois é o principal causador do impacto e o mesmo deve mensurar qual é a sua pegada ecológica e definir estratégias para minimizar os impactos causados pela sua ação.

Nesse sentido surge o conceito que, para Andrade (2006), Sebastião (2010) e Parente (2007), o Holiday EFM (HEFM) ou em português "Pegada de Férias" que é a ferramenta aplicada para calcular os impactos do turismo/turista em determinada região. Também pode ser usada para mensurar e comparar o uso de recursos de diferentes tipos de comportamentos e a escolhas dos turistas (Sebastião, 2010). Após a realização do cálculo do EFM, as organizações devem estabelecer parâmetros de mensuração para obter a certificação ambiental, que, no setor turístico, as empresas podem ser certificadas em 


\section{(6)

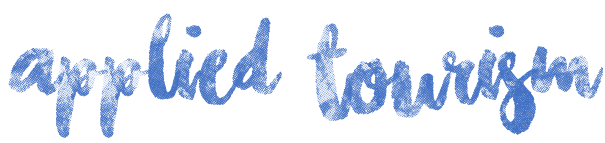

Volume 2, número 1,2017, p. 176-200

função dos meios de hospedagem, agências de viagens, parques naturais, restaurantes e outros do gênero (Neiman, 2010).

\section{METODOLOGIA}

O caráter de pesquisa aplicada assume técnicas quantitativas e qualitativas (Roesch, 2011) com bases exploratórias. Dentre os instrumentos de pesquisa utilizados estão os formulários com questões abertas e fechadas (Dencker, 2001) e documentos, tais como a Ficha Nacional do Hóspede - FNH, faturas de consumo de água, energia, entre outros documentos de registro interno e referências bibliográficas.

Utilizou-se para a delimitação das variáveis no primeiro objetivo: eletricidade, mobilidade, resíduos, água e uso do solo (Parente, 2007; Silva, Silva \& Enders, 2012; Quercus, 2014), pois verificou-se que essas são as mais usadas, sobretudo, a limite de estudos voltados para o setor de meios de hospedagem, e a prerrogativa do elemento carbon free mostrar-se quase nulo para o setor dado as múltiplas inter-relações do setor e o custo dispendido.

Para atingir o segundo objetivo fez-se necessário definir as variáveis de deslocamento dos turistas (Parente, 2007; Green Nation, 2014) como tipologia do meio de transporte, procedência, tempo de deslocamento e escalas/conexões. Justifica-se o interesse pois entende-se que direta ou indiretamente os passivos dos turistas também podem fazer parte da pegada ambiental dos meios de hospedagem.

Como medidas compensatórias adaptadas à realidade do empreendimento em questão, optou-se pela educação ambiental, plantio de árvores e 3Rs (Ministério do Meio Ambiente, SOS Mata Atlântica, PassaporteVerde, Iniciativa Verde e Hóspedes Da Natureza). Estas ações estão elencadas nos principais encartes das organizações relacionados ao meio ambiente.

Utilizou-se uma amostra probabilística como público alvo de pesquisa (Barbetta, 2011). Considerando o número total de visitantes do ano de 2013 de Itaipu Binacional e Cataratas 


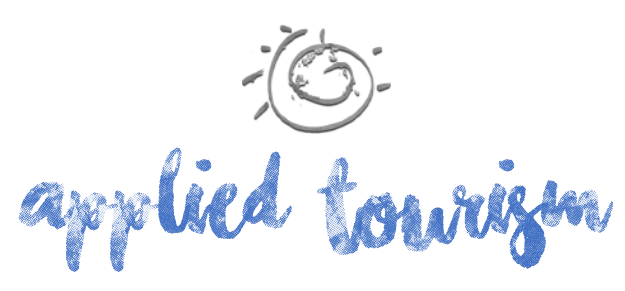

Volume 2, número 1,2017, p. 176-200

do Iguaçu, obteve-se a seguinte subpopulação, de 237 pessoas para as Cataratas do Iguaçu e 112 pessoas para a Itaipu Binacional. Com esse dado pode-se chegar ao cálculo da amostra probabilística.

O procedimento de coleta dos dados caracteriza-se pelo uso de metodologias múltiplas (Dencker, 2001) e a técnica de análise dos dados é o método estatístico de frequência e associação (Andrade, 2009) e análise de conteúdo (Marconi \& Lakatos, 1999) referente os resultados dos indicadores.

Realizou-se o pré-teste no empreendimento entre os dias 02 e 18 de agosto de 2014, no momento do check-in (a ideia inicial era com demanda real do hotel) e virtualmente nos emails dos hóspedes habitué (com o uso da ferramenta Google Docs e links na Fanpage do hotel), contudo, devido à baixa temporada e interesse dos mesmos não houve um número significativo de respondentes (apenas 22), mas que ajudarem em ajustes pontuais relacionados à linguagem, sobretudo, na mudança de foco da pesquisa para demanda potencial como estudo mercadológico, como foco no diferencial competitivo relacionado ao marketing verde como elemento atrativo para demanda (sugestão de estudos futuros).

Após realizar essas modificações, foram aplicados 348 formulários nos dias 23 e 24 de agosto de 2014, nos pontos turísticos Itaipu Binacional e Cataratas do Iguaçu, sendo e 150 e 198 respectivamente (seguindo o padrão de estratificação percentual).

\section{APRESENTAÇÃO E ANÁLISE DOS DADOS: IDENTIFICAÇÃO DO EFM}

O EFM é uma ferramenta que consiste em calcular o impacto ambiental causado pelo indivíduo. Conforme apresentado na metodologia o $1^{\circ}$ objetivo consiste em calcular a pegada ambiental dos principais itens desencadeadores da organização em estudo.

Para responder este $1^{\circ}$ objetivo foi realizada uma ampla pesquisa bibliográfica sobre o tema, tendo em vista que o assunto é recente. As principais fontes de informações foram artigos 


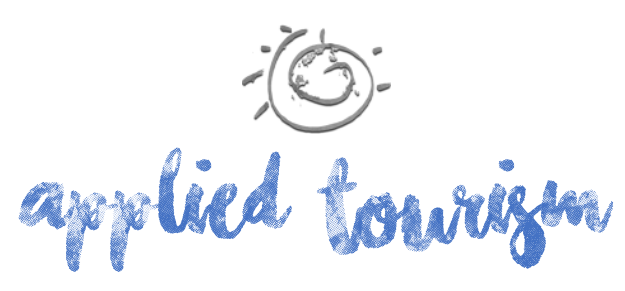

Volume 2, número 1,2017, p. 176-200

científicos, dissertações de mestrado e teses de doutorado. Para complementar e entender o tema pesquisado identificou-se a necessidade de dialogar com alguns pesquisadores da área tais como: Aparecido Parente - Mestre em Administração, Cláudio Evaldo - Engenheiro Ambiental, Bere Adams - Projeto Apoema, Felipe Marques Engenheiro Ambiental, Rodrigo Felismino - Diretor da Consvita, Nuno Forner - Integrante do Grupo Quercus entre outros. Esses estudiosos contribuíram de forma significativa com sugestões e informações de relevância para essa pesquisa bem como para aplicabilidade desse projeto.

Para enriquecer ainda mais o estudo foram contatadas algumas instituições ambientais renomadas tais como: SOS Mata Atlântica, Iniciativa Verde, Eco-Conservation,Eartbday, Projeto Água, Fundação Calouste Gulbenkian, UFMG, IEMinho, WWF, ESALQ e USP, das quais obteve-se que basicamente replicavam/reforçavam as informações contidas nos seus respectivos sites.

Dentre essas pesquisas a que mais adequada para este estudo foi um artigo concedido pelo engenheiro Felipe Marques do Ministério do Meio Ambiente do Canadá (2014), com um estudo voltado a "Melhor Metodologia para quantificação das emissões de Gases de Efeito Estufa focado para meios de hospedagem". Explica-se que nessa pesquisa que foi avaliado um total de cinco propriedades (2 em Vancouver, 1 em Edmonton, 1 em Vitória e 1 em Prince George). As propriedades no oeste do Canadá fornecem uma amostragem espacial de locais em climas diferentes para representar diferentes padrões de consumo de energia, assim variaram em tamanho de 132 quartos e 299.

Com base no estudo o fator de emissão para uma noite de estadia foi calculado dividindose o total de emissões de Gases de Efeito Estufa-GEE para a amostra de hotéis pelo número de pernoites assumindo ocupação completa, conforme o quadro 01.

Quadro 01 - Fórmula de emissão de carbono Fator de Emissão (kg /CO2/noite) $=51.310$ ts de CO2 e * 1000/7238 (UHs *365 noites) Fonte: Estudo do Ministério do Meio Ambiente do Canadá(2013). 


\section{(2)

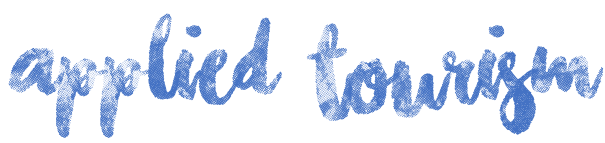

Volume 2, número 1,2017, p. 176-200

Quadro 03 - Cálculo de quantidade de árvores versus $\mathrm{CO} 2$

1 hag $=10.000 \mathrm{~m}^{2}=1.000$ árvores

$5.400 / 1.000=5,4 \mathrm{Kg} \mathrm{CO} 2$

$12,43 / 5,4=2,30$

Fonte: Dados da Pesquisa, com base no estudo Ministério do Meio Ambiente do Canadá (2013).

Para melhor entendimento do cálculo explica-se que $10.000 \mathrm{~m}^{2}$ equivale a 1 hag, e isso corresponde a 5,4 toneladas consequentemente $5,400 \mathrm{Kg}$ de CO2. Dessa forma divide-se o valor de CO2 pela quantidade de árvores (1000) para obter o quanto cada árvore sequestra de CO2. Utilizando a referência de 12,43 Kg de CO2, divide-se pelo Kg de CO2 o que resulta em 2,3 árvores para compensar o que um quarto gera de carbono por noite. Realizou-se o cálculo do EFM com base no Estudo do Ministério do Meio Ambiente do Canadá (2013), dessa forma o quadro 04 apresenta o cálculo do EFM do hotel estudado.

Quadro 04 - Cálculo do EFM Eduardo Hotel

$12,43 * 20 / 70=3.55$ Árvore Pax dia

Fonte: Dados da Pesquisa (2014), com base Ministério do Meio Ambiente do Canadá(2013).

Para este cálculo, considerou-se que o empreendimento possui 20 UH's com capacidade para 70 leitos, tendo em vista que 12,43 é o número de kg de CO2, o que resultou em 3,55 de árvore pax dia. Destaca-se que o cálculo é complexo, pois, abrange todo ciclo de vida considerando todos os insumos necessários para gerar o serviço, o que torna o resultado inviável pelo alto número de árvores necessárias para neutralizar o CO2. Com base na calculadora SOS Mata Atlântica, para plantar uma árvore o valor a ser pago é de $\mathrm{R} \$ 12,00$ (pessoa jurídica), considerando que o valor da diária do hotel é de $\mathrm{R} \$ 90,00$ para quarto Single em alta temporada (e $\mathrm{R} \$ 60,00$ na baixa), o valor para neutralizar a hospedagem equivale a 47,33\% desse valor, o que torna inviável tal prática.

Ao analisar o resultado fez-se necessário pesquisar outros meios de cálculo, para tanto buscou-se as calculadoras online nos seguintes sites: SOS Mata Atlântica, Iniciativa Verde, WWF, Global Footprint Network e Green Steps. Esses sites apresentam calculadora para 


\section{(6)

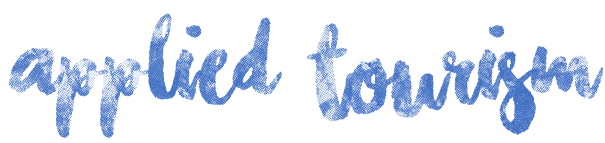

Volume 2, número 1,2017, p. 176-200

pessoa física, que averiguavam os seguintes indicadores: água, energia, alimentação, consumo, transporte, resíduos. Através desses meios percebeu-se que alguns contemplavam a pesquisa, todavia outros não, pois comprometeriam o resultado deste.

Observou-se o site internacional Quercus, entretanto, fora o que mais se adaptou aos indicadores do estudo, cujo apresenta valores em Euro (€). Para sanar este impasse, realizou-se a conversão através do site do Banco Central do Brasil, com os valores do câmbio na data do dia 21/09/2014. Portanto, a justificativa para a escolha desse site deve-se ao programa desenvolvido pelo mesmo, denominado Ecopegada, que tem a finalidade de realizar o cálculo do EFM para pessoa jurídica, que abrange os principais indicadores que uma empresa precisa para desenvolver as suas atividades, tais como:

- Energia: baseado em consumo de eletricidade e gás natural;

- Mobilidade: que constitui em gasolina e transporte em geral;

- Resíduos: divido entre reciclável, orgânico e rejeito;

- Água: consumo de água; e

- Uso do solo; o espaço relativo à área ocupada pela organização em metros quadrados.

Estes dados foram coletados através de documentos relacionados aos indicadores dos 12 meses do ano de 2013. Para melhor entendimento o resultado se dá a um fator de equivalência que é o hag., que significa hectares globais. Que de acordo com Forner (2010, p. 6) "é equivalente a um hectare de espaço biológico produtivo com uma produtividade mundial média". O tamanho de um hectare pode ser comparado com o tamanho de um campo de futebol, que corresponde a 10,800 metros quadrados, ou seja, 1,08 hectares.

A tabela do EFM é composta pelos desencadeadores tais como: mobilidade, eletricidade, resíduos, água e uso do solo, após o cálculo identificou-se o hag. mensal sendo dividido pelo número de pax mês no qual resultou em hag. per capita. Tendo em vista o objetivo deste trabalho que é de calcular o valor anual do EFM, somou-se o total de hag. dos 12 


\section{ayplied tow tow}

Volume 2, número 1,2017, p. 176-200

meses de 2013 que corresponde a 19,59 HAG. Portanto, pode-se perceber na tabela 01, que o desencadeador que mais influenciou nesse resultado foi o consumo de água em todos os meses, equivalente a média de $69,52 \%$ do hag. anual, um número considerado alto. 


\section{applied towigh}

Volume 2, número 1, 2017, p. 176-200

Tabela 01 - EFM Eduardo Hotel

\begin{tabular}{|c|c|c|c|c|c|c|c|c|c|c|c|c|}
\hline- & Jan. & Fev. & Mar. & Abr. & Mai. & Jun. & Jul. & Ago. & Set. & Out. & Nov. & Dez. \\
\hline Reciclável & $64 \mathrm{Kg}$ & $24,2 \mathrm{Kg}$ & $36,4 \mathrm{Kg}$ & $45,7 \mathrm{Kg}$ & $34,3 \mathrm{Kg}$ & $46,3 \mathrm{Kg}$ & $44,6 \mathrm{Kg}$ & $44,4 \mathrm{Kg}$ & $34,8 \mathrm{Kg}$ & $32,6 \mathrm{Kg}$ & $50,2 \mathrm{Kg}$ & $74,1 \mathrm{Kg}$ \\
\hline Orgânicos & $91,3 \mathrm{Kg}$ & $35 \mathrm{Kg}$ & $51,6 \mathrm{Kg}$ & $60,6 \mathrm{Kg}$ & $53,2 \mathrm{Kg}$ & $64,8 \mathrm{Kg}$ & $59,5 \mathrm{Kg}$ & $67,3 \mathrm{Kg}$ & $63,8 \mathrm{Kg}$ & $59,3 \mathrm{Kg}$ & $38 \mathrm{Kg}$ & $42,4 \mathrm{Kg}$ \\
\hline Rejeito & $19 \mathrm{Kg}$ & $19 \mathrm{Kg}$ & $18 \mathrm{Kg}$ & $17 \mathrm{Kg}$ & $16 \mathrm{Kg}$ & $17 \mathrm{Kg}$ & $16 \mathrm{Kg}$ & $16 \mathrm{Kg}$ & $15 \mathrm{Kg}$ & $16 \mathrm{Kg}$ & $16 \mathrm{Kg}$ & $17 \mathrm{Kg}$ \\
\hline $\begin{array}{l}\text { Total hag. dos } \\
\text { resíduos }\end{array}$ & 0,0275 & 0,0156 & 0,0188 & 0,0210 & 0,0175 & 0,0721 & 0,0203 & 0,0205 & 0,0175 & 0,0173 & 0,0211 & 0,0277 \\
\hline Gás & $\mathrm{R} \$ 78,33$ & $\mathrm{R} \$ 78,33$ & $\mathrm{R} \$ 78,33$ & $\mathrm{R} \$ 78,33$ & $\mathrm{R} \$ 78,33$ & $\mathrm{R} \$ 78,33$ & $\mathrm{R} \$ 78,33$ & $\mathrm{R} \$ 78,33$ & $\mathrm{R} \$ 78,33$ & $\mathrm{R} \$ 78,33$ & $\mathrm{R} \$ 78,33$ & $\mathrm{R} \$ 78,33$ \\
\hline Luz & $\mathrm{R} \$ 2.153,51$ & $\mathrm{R} \$ 2.110,51$ & $\mathrm{R} \$ 1.947,11$ & $R \$ 1.658,40$ & $\mathrm{R} \$ 1.250,24$ & $R \$ 986,00$ & $\mathrm{R} \$ 581,98$ & $\mathrm{R} \$ 598,00$ & $\mathrm{R} \$ 823,43$ & $\mathrm{R} \$ 770,00$ & $\mathrm{R} \$ 842,00$ & $\mathrm{R} \$ 842,00$ \\
\hline $\begin{array}{l}\text { Total de hag. } \\
\text { de gás e luz }\end{array}$ & 0,3637 & 0,3566 & 0,2324 & 0,2815 & 0,2137 & 0,1698 & 0,1087 & 0,1054 & 0,1428 & 0,0239 & 0,1459 & 0,1459 \\
\hline Gasolina & $R \$ 205,00$ & $\mathrm{R} \$ 246,81$ & $\mathrm{R} \$ 237,55$ & $R \$ 212,00$ & $R \$ 209,22$ & $\mathrm{R} \$ 140,00$ & $\mathrm{R} \$ 216,00$ & $R \$ 169,00$ & $\mathrm{R} \$ 189,10$ & $R \$ 205,00$ & $\mathrm{R} \$ 165,00$ & $\mathrm{R} \$ 182,00$ \\
\hline $\begin{array}{c}\text { Total hag. } \\
\text { mobilidade/ } \\
\text { Gasolina }\end{array}$ & 0,0357 & 0,0430 & 0,0413 & 0,0369 & 0,0410 & 0,0244 & 0,0376 & 0,0294 & 0,0329 & 0,0357 & 0,0287 & 0,0322 \\
\hline Água & $\mathrm{R} \$ 819,00$ & $\mathrm{R} \$ 1.101,40$ & $R \$ 1.092,55$ & $\mathrm{R} \$ 979,12$ & $R \$ 936,85$ & $R \$ 654,00$ & $\mathrm{R} \$ 661,68$ & $\mathrm{R} \$ 600,00$ & $\mathrm{R} \$ 773,00$ & $\mathrm{R} \$ 683,68$ & $\mathrm{R} \$ 754,64$ & $\mathrm{R} \$ 877,00$ \\
\hline $\begin{array}{l}\text { Total hag. } \\
\text { água }\end{array}$ & 1,05 & 1,41 & 1,40 & 1,26 & 1,20 & 1,27 & 0,8500 & 0,7708 & 0,9931 & 0,8783 & 0,9694 & 1,61 \\
\hline Solo & $850,22 \mathrm{~m}^{2}$ & $850,22 m^{2}$ & $850,22 m^{2}$ & $850,22 m^{2}$ & $850,22 m^{2}$ & $850,22 m^{2}$ & $850,22 m^{2}$ & $850,22 m^{2}$ & $850,22 m^{2}$ & $850,22 m^{2}$ & $850,22 m^{2}$ & $850,22 m^{2}$ \\
\hline Total hag. solo & 0,2399 & 0,2399 & 0,2399 & 0,2399 & 0,2399 & 0,2399 & 0,2399 & 0,2399 & 0,2399 & 0,2399 & 0,2399 & 0,2399 \\
\hline $\begin{array}{l}\text { TOTAL DE } \\
\text { HAG }\end{array}$ & 1,72 & 2,07 & 1,94 & 1,84 & 1,72 & 1,77 & 1,26 & 1,17 & 1,43 & 1,20 & 1,41 & 2,06 \\
\hline $\begin{array}{c}\text { №. Total de } \\
\text { Pax }\end{array}$ & 686 & 530 & 501 & 408 & 260 & 425 & 468 & 374 & 422 & 500 & 408 & 493 \\
\hline $\begin{array}{c}\text { Resultado Per } \\
\text { Capita }\end{array}$ & 0,0003 & 0,0004 & 0,0004 & 0,0005 & 0,0007 & 0,0004 & 0,0003 & 0,0003 & 0,0003 & 0,0002 & 0,0003 & 0,0004 \\
\hline
\end{tabular}

Fonte: Elaborado pelos autores, com base nos dados fornecidos pelo Eduardo Hotel (2014). 


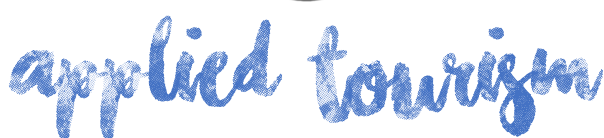

Volume 2, número 1,2017, p. 176-200 


\section{(6)

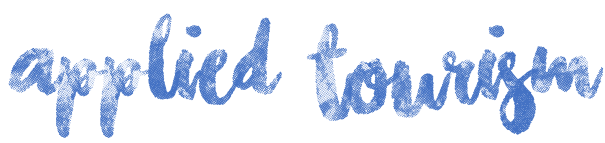

Volume 2, número 1,2017, p. 176-200

Tendo em vista que três quartos da superfície da terra são compostos por água, formados por oceanos, lagos, rios, pântanos, geleiras, manguezais e calotas polares. Do total de 1386 $\mathrm{km}^{3}$, apenas 2,5\% desse total são de água doce, ainda 68,9\% são para formação das geleiras o que significa que apenas $0,3 \%$ da água do planeta estão à disposição podendo ser consumida direta da natureza (Souza Filho, 2012).

Outro elemento a ser considerado é a discrepância de valores nos meses de fevereiro onde o valor é de 2,07 hag., e agosto corresponde a 1,17 hag., isso se deve a sazonalidade. De acordo com Cunha (1997, p. 189) a sazonalidade traduz-se pela distribuição da procura ao longo do ano de forma desigual, provocando uma concentração em alguns meses mais do que os outros, e deriva de fatores climáticos, demográficos, econômicos e outros.

Um fator que deve ser observado são as condições climáticas, pois o clima do município é subtropical e nos meses de dezembro a março a média de temperatura é de $40^{\circ} \mathrm{C}$ e no inverno a temperatura pode chegar a $-1^{\circ} \mathrm{C}$ (Instituto Brasileiro de Meteorologia). Em relação aos meses de verão o consumo de água e energia é superior aos demais meses, devido à quantidade de tempo no banho e o uso constante do ar-condicionado.

Um item a ser considerado relevante é a relação entre o número de hóspede com o número de hag., do mês de janeiro onde houve um número superior de hóspedes (686), comparados aos demais meses, o seu número de hag. $(1,72)$ é considerado baixo, contudo no mês de maio o número de hóspede (260) apresentou o menor número de clientes do hotel do ano de 2013, porém o seu hag. é de 1,72 sendo semelhante ao mês de janeiro onde o número de pax foi maior que duas vezes.

A partir dessas informações, acredita-se que no mês de janeiro esses dados se devem aos seguintes motivos: alta temporada, período de férias, recesso de fim de ano consequentemente o poder aquisitivo é maior pelo pagamento de férias e décimo terceiro, influenciando diretamente na programação da viagem, ou seja, supõe que esse indivíduo que vem a cidade nesse período gasta com entretenimento reduzido consideravelmente a 


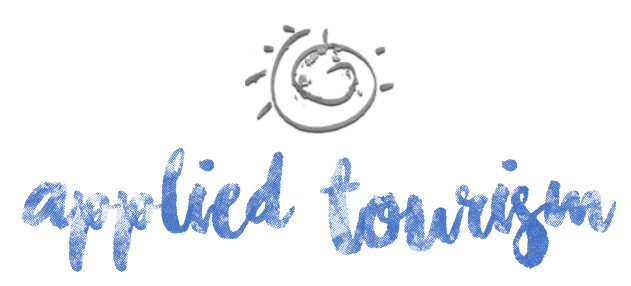

Volume 2, número 1,2017, p. 176-200

sua permanência dentro do hotel, refletindo assim na geração do hag. A título de informação, o relatório anual das Cataratas do Iguaçu no mês de janeiro foi considerado o mês mais visitado pelos turistas chegando a 184.784 visitações.

Tendo em vista que a visitação influência na quantidade de hospedagem, consequentemente no aumento do hag., o segmento hoteleiro é um dos principais causadores dos efeitos ambientais negativos gerados pelos hóspedes (Andrade, Tavares \& Valle, 2000), isso se dá ao consumo elevado de água, energia e geração de resíduos sólidos, como pode ser observado o Eduardo Hotel impactou no ano de 2013 19,59 hag. (hectares globais).

Para minimizar os impactos causados pelo Eduardo Hotel, buscou-se a melhor alternativa para compensação de carbono. Para isso encontrou-se como medida o plantio de árvores como sendo uma das principais recomendações dos especialistas contra o aquecimento global, pois elas são responsáveis pelo chamado sequestro de CO2 (dióxido de carbono), um dos gases causadores do efeito estufa, com a ajuda do engenheiro Felipe Marques foi transformado o hag. em quantidade de $\mathrm{CO} 2$ transformando em número de árvores. O quadro 05 representa essa fórmula.

Quadro 05 - Fator de equivalência do Hag.

\begin{tabular}{|l|l|}
\hline Hag. & Equivalência \\
\hline 1 hag & 1000 árvores \\
\hline 1 hag & 5.4 toneladas de CO2 \\
\hline $0,0054 * 1000=5,4$ toneladas de CO2 & \\
\hline
\end{tabular}

Fonte: Dados da Pesquisa com base nas informações do engenheiro Felipe Marques (2014).

Com essas informações, foi possível calcular quantas árvores seriam necessárias para compensar o impacto do empreendimento, dado que a referência é de 1000 árvores por hectares, sendo que em média as espécies paranaenses "sequestram" 0,0054 toneladas de CO2 por ano. Com base nessas informações obteve-se o cálculo específico do empreendimento, demonstrado no quadro 06. 


\section{(2)

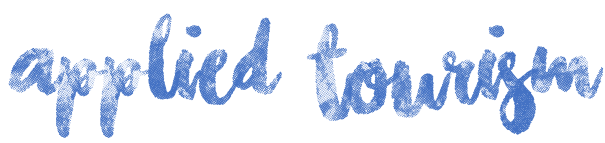

Volume 2, número 1,2017, p. 176-200

Quadro 06 - Cálculo do hag. do Eduardo Hotel

Hag. anual: $19,59 * 1000$ árvores $=19,590 / 5475=3,578$ árvores por pax/dia

Fonte: Dados da Pesquisa com base nas informações do engenheiro Felipe Marques (2014).

Considerando que 19,590 árvores são necessárias para compensar o impacto causado pelos hóspedes de 2013 que totalizam 5475 pax, essa divisão resulta em um total de 3,78 árvores pax/dia. Assim, para saber o valor a ser acrescido na diária, fez-se necessário calcular a quantidade de árvores que cada hóspede deveria plantar diariamente para compensar seu passivo ambiental.

Realizou-se uma pesquisa com a finalidade de encontrar os valores mais acessíveis para o plantio de árvores em entidades não governamentais que tem como objetivo a preservação do meio ambiente, tais como: WWF, Greensteps, Iniciativa Verde, SOS Mata Atlântica e Plante Árvores dentre outros. Ao analisar essas organizações, verificou-se que o valor das árvores para pessoa jurídica tem um valor alto para o empreendimento, dentre os valores encontrados o menor valor foi de $\mathrm{R} \$ 12,00$ para pessoa jurídica pela instituição SOS Mata Atlântica, desta forma esse valor inviabiliza o plantio de árvores, pois para compensação de um pax por ano o valor é de $\mathrm{R} \$ 45,36$ (3,78 árvores* $\$ 12,00)$, o que representa 50,4\% do valor da diária.

Assim sendo buscou-se uma alternativa encontrada para diminuir o valor foi o plantio de árvores para pessoa física que de acordo com o SOS Mata Atlântica é de $\mathrm{R} \$ 2,00$ para compensação de pax por ano assim o valor total é $\mathrm{R} \$ 7,56$ (3,78 árvores*R\$2,00), o que corresponde a 8,4\% na diária, considerando ainda que o proprietário do empreendimento já possua cadastro no site facilitando a compra das mudas.

Outra perspectiva de cálculo foi média do hag. anual dividida pela média de pessoas dia. Com a finalidade de melhorar a fórmula apresentada anteriormente resolveu-se aperfeiçoála (conforme Quadro 07) para obter dados mais específicos para realidade do hotel. 


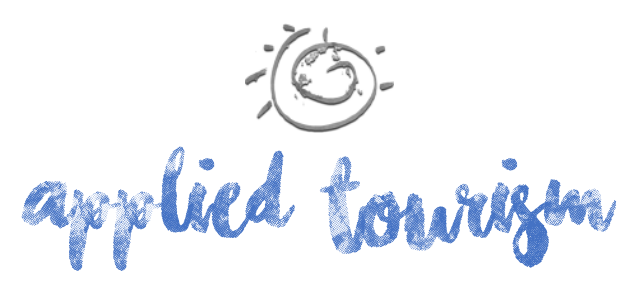

Volume 2, número 1,2017, p. 176-200

Quadro 07 - Cálculo do hag. do Eduardo Hotel

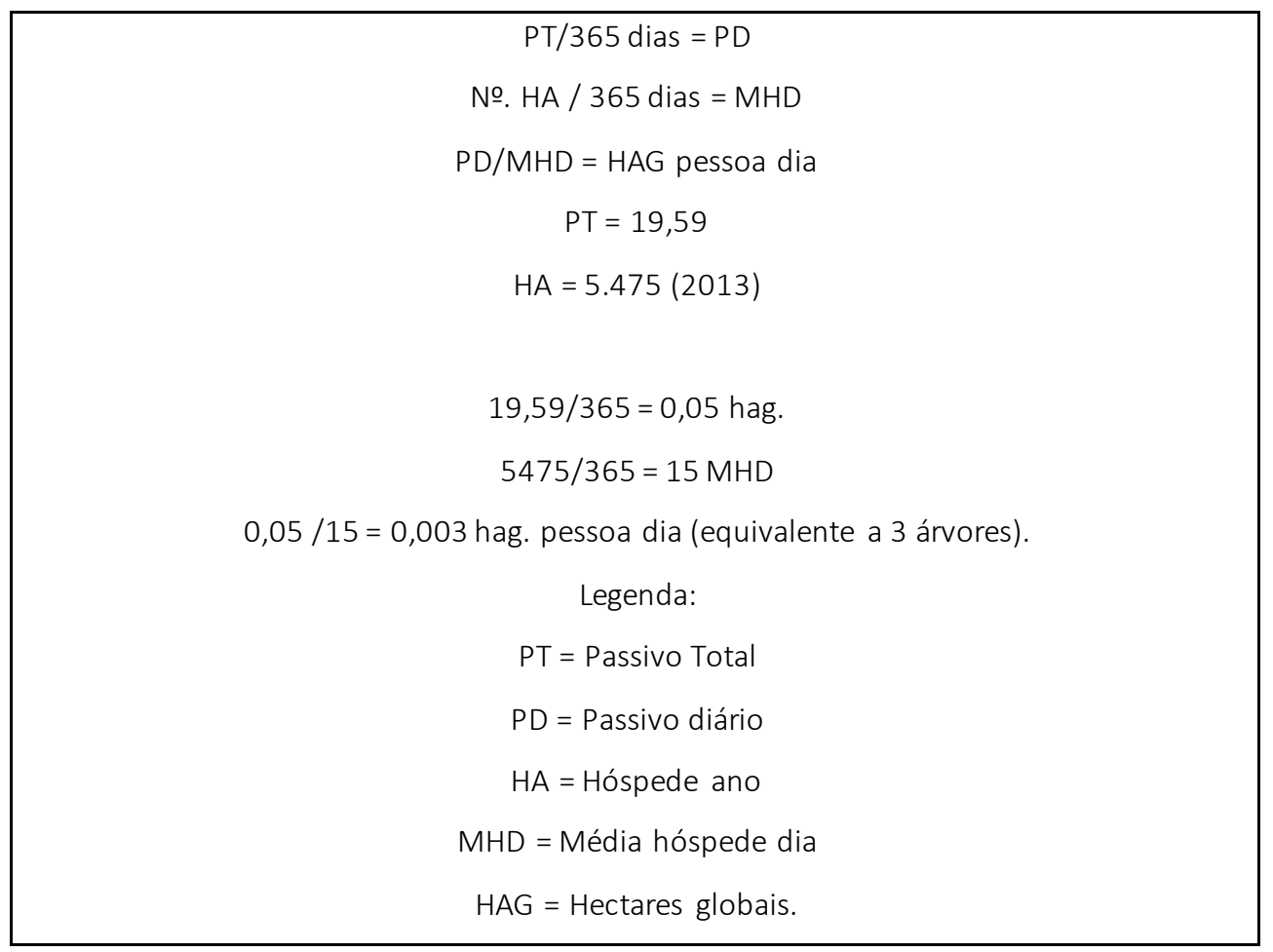

Fonte: Elaborado pelos autores, com base no cálculo do Engenheiro Felipe Marques (2014).

Ao realizar a comparação do cálculo utilizando como base os valores de mudas SOS Mata Atlântica, com o faturamento anual do empreendimento pode-se perceber que o valor gasto em árvores compromete o lucro líquido da organização. Tendo em vista que é inviável tal prática buscou-se uma nova alternativa para o empreendimento compensar o seu passivo ambiental no qual sugere-se como primeira opção: o hóspede poderá optar por neutralizar o seu impacto na hora do check-in, com valores pré-estabelecidos pelo Eduardo Hotel. A melhor opção para o empreendimento é disponibilizar 10\% do seu lucro líquido mensal para aquisição de mudas através do site SOS Mata Atlântica.

Para entender as particularidades dos hóspedes, que são os geradores desse resultado, para tanto durante o período de 15 dias foi aplicado um questionário com os hóspedes do empreendimento, contudo devido ao período de baixa temporada, não alcançou o número necessário de questionários. Desse modo a pesquisa teve que ser realizada com possíveis 


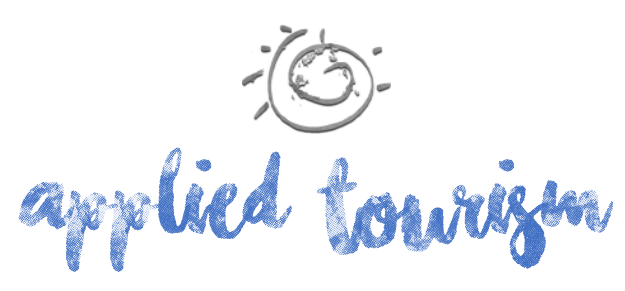

Volume 2, número 1,2017, p. 176-200

hóspedes do Hotel a fim de identificar o perfil sócio econômico e comportamental da demanda potencial, que será apresentado no próximo tópico.

\section{VERIFICAÇÃODO HFEM DA DEMANDA POTENCIAL}

Para realizar o cálculo foi feita uma pesquisa bibliográfica a fim de identificar a fórmula do cálculo do HEFM, indicado pelo o pesquisador Parente (2007) no intuito de optar pela fórmula que engloba seus indicadores, para assim ter um resultado concreto. Nessa busca para atingir mais informações sobre a fórmula, percebeu-se que por se tratar de um tema recente, os estudos sobre o assunto replicavam basicamente as informações teóricas.

Dessa forma, solicitou a colaboração de Parente a fim de encontrar uma calculadora eletrônica que fosse capaz de identificar o HEFM, no qual verificou-se que existem diversas possibilidades de calculadora online, tais como o TripZero, que é uma agência de viagens que apresenta uma consciência ambiental e desse modo, a organização compensa a pegada de carbono do turista que adquire o serviço da agência de viagem.

A calculadora abrange a questão de hospedagem e o deslocamento do indivíduo que gera um resultado de carbono que o turista está emitindo com sua viagem, porém por se tratar de um site internacional a unidade de medida utilizada não é compatível com a realidade brasileira, e por isso não foi possível ter um resultado concreto e confiável do HEFM.

Outro site consultado foi o Carbônica que é uma instituição internacional que se preocupa com o aquecimento global, e que possui uma calculadora que abrange o tipo de viagem que indivíduo irá realizar, sendo muito mais específico com relação às atividades do turista no seu momento de férias, desta forma não foi possível utilizar essa calculadora.

Percebeu-se que as calculadoras consultadas tinham informações que replicavam em outros demais sites, e que os dados para realização do cálculo não eram compatíveis com a realidade local, pois os indicadores não atendiam aos critérios da pesquisa. Desta forma, 


\section{;)

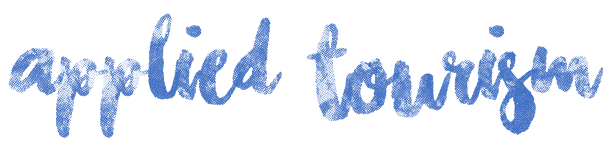

Volume 2, número 1,2017, p. 176-200

através de texto verificou-se que o principal indicador do impacto do turista em seu momento de férias é o deslocamento, ou seja, o meio de transporte que ele utilizou para viajar. De acordo com Borges et al (2007, p. 4) "O Monóxido de carbono (CO) emitido pelos automóveis é o grande responsável pela poluição atmosférica e causa uma série de efeitos nocivos ao corpo humano e ao meio ambiente". Esse conceito justifica a importância de se calcular o deslocamento do indivíduo.

Com o enfoque de calcular o deslocamento do turista sendo um dos principais indicadores do HEFM, buscou-se a calculadora online que obtinha esse fator mais apurado, encontrouse o site Green Nation, que é site brasileiro com apoio de vários parceiros que tem como objetivo de ser um ambiente colaborativo, online que interage com as pessoas para convergir cultura, informação e proteção ambiental a partir de questões que envolvem o futuro do planeta.

A calculadora eletrônica consiste em equacionar o deslocamento utilizando o meio de transporte versus trajeto. Para tanto utiliza-se estimativas baseadas e adaptadas do The Greenhouse Gas Protocol e ferramentas estabelecidas pelo World Business Council for Sustaineble Development (WBCSD) e pelo World Resources Institute (WRI). O resultado do cálculo é dado em quantidade de $\mathrm{CO} 2$ emitido e o próprio site fornece a informação de quantas árvores seriam necessárias para compensar a emissão de carbono.

Para identificar o HEFM dos turistas, foram inclusos os 348 questionários na calculadora virtual. Constatou-se que $47 \%$ dos entrevistados utilizaram o avião como meio de transporte. Sendo que, o querosene é o principal combustível utilizado por aeronaves e sua queima dá origem a diversos poluentes perigosos que contribuem com o aquecimento global, como o monóxido e o dióxido de carbono, os hidrocarbonetos gasosos, e os óxidos de nitrogênio. A partir desse pressuposto, o Brasil registrou um aumento de 8,1 \% na demanda de voos doméstico no mês de abril de 2014. Desse modo, pode-se perceber que as pessoas estão viajando cada vez mais, e não estão minimizando a sua emissão de carbono. 


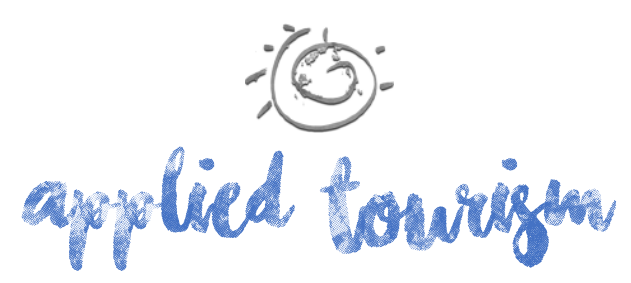

Volume 2, número 1,2017, p. 176-200

Após o cálculo, verificou-se que a soma total de CO2 dos entrevistados foi 62,704 Kg, logo, soma de árvores correspondente à compensação do deslocamento desses turistas seria de 316,48 árvores.

Vale destacar que, o tipo de transporte utilizado influencia na quantidade de emissão de carbono, pode-se exemplificar esta afirmativa, uma pessoa que faz o uso do carro em viagem de São Paulo - SP a Foz do Iguaçu - PR, emite 16,8 Kg de CO2, o que equivale a 0,08 árvores, sendo que mesmo trajeto utilizando o avião lança na atmosfera 200,02 Kg de CO2 corresponde a 1 árvore, logo, à quantidade de emissão entre os tipos de transporte são discrepantes, como pode-se observar no gráfico 01.

Gráfico 01 - Emissão e compensação

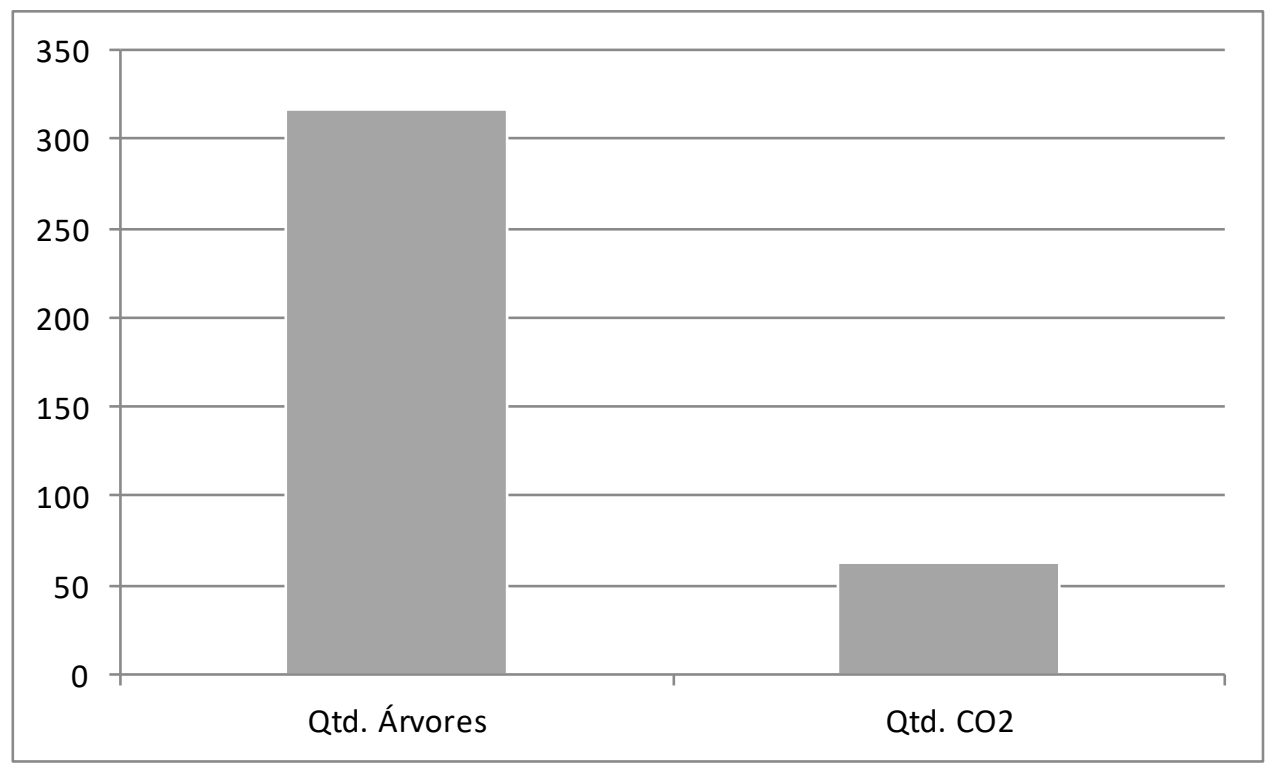

Fonte: Dados da Pesquisa (2014).

Para o Eduardo Hotel assumir a responsabilidade de plantar árvores pelo deslocamento dos turistas, ou melhor, do seu potencial hóspede, realizou-se um paralelo de quanto custaria uma árvore.

Ao rigor da teoria dos estudos, como é o estudo Canadense que foi discutido no $1^{\circ}$ objetivo afirma que o meio de hospedagem também é responsável pelo deslocamento o valor para 


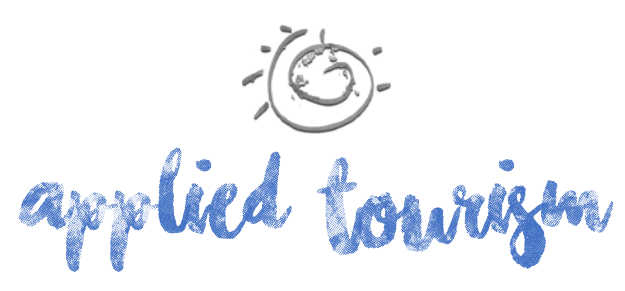

Volume 2, número 1,2017, p. 176-200

neutralizar a emissão através de plantio de árvores, não se torna viável para o empreendimento, pois considerando que são 316,48 árvores a serem plantadas no custo de $R \$ 12,00$ esse montante equivale a $R \$ 3.797,76$ para organização sendo um valor discrepante, pois já para pessoa física equivale a $\mathrm{R} \$$ 632,96.

Visto que esse valor é para neutralizar o deslocamento, acredita-se que a companhia aérea deveria se responsabilizar pela emissão de carbono dos seus passageiros, uma vez que o seu meio de transporte é o mais impactante, vale destacar que as montadoras de veículos/ônibus também possuem a sua fração no impacto.

Outro ponto é que os turistas viajam para conhecer o destino, e sua hospedagem é uma consequência, tanto é que $84 \%$ dos entrevistados responderam como principal motivo de viagem é o lazer, desse modo, frente à tipologia primordial dos atrativos da localidade "naturais", o destino turístico deveria neutralizar a emissão de carbono.

Vale destacar, o turismo CO2 Legal tem como objetivo promover o envolvimento e o comprometimento de todos os atores sociais que, direta ou indiretamente, se relaciona com o turismo na região a fim de minimizar os impactos ambientais. Para isso, as empresas e negócios ligados à cadeia produtiva deste setor (pousadas, hotéis, restaurantes, bares, lavanderia, receptivos, entretenimento e entre outros), bem como o turista, deveriam compensar as emissões de $\mathrm{CO} 2$, geradas pelos seus negócios, e pelas suas viagens ao destino.

Dessa forma, com a aplicação efetiva de todas as empresas do setor o destino se tornaria Carbon Free sendo que todos os envolvidos estariam dispostos a contribuir para neutralizar as emissões de gases, o que colocaria Foz como destino destaque no cenário internacional, como por exemplo, a cidade de Itacaré - BA no Brasil. Com essa divulgação do Hotel sendo Carbon Free, se torna um diferencial competitivo para empreendimento. 


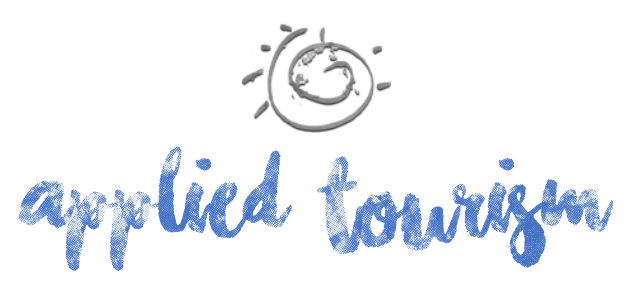

Volume 2, número 1,2017, p. 176-200

Com a concorrência acirrada entre os meios de hospedagens da mesma categoria ou inferior, é necessário buscar alternativas de diferencial competitivo, pois ainda os turistas levam em consideração o preço na hora de escolher o hotel.

\section{CONSIDERAÇÕES FINAIS}

A presente pesquisa teve como finalidade expor as considerações e discussões acerca do tema "Ecological Footprint Method" - EFM, um assunto recente nas organizações. O estudo justifica-se pela a abrangência e complexidade do método, dado ao fato de uma tendência para assuntos relacionados à gestão ambiental. Buscou-se identificar os indicadores ambientais e medidas compensatórias aplicáveis como estratégia mercadológica a fim de criar um diferencial competitivo ao Eduardo Hotel.

O primeiro objetivo atingido, foi identificar o EFM dos desencadeadores dos 12 meses do ano de 2013 do Eduardo Hotel. Neste objetivo verificou-se que há relações diretas entre os desencadeadores (água, energia, resíduos, uso do solo e mobilidade), e as oscilações do perfil comportamental do hóspede, junto a variação das condições climáticas da cidade de Foz.

Algumas barreiras foram durante a pesquisa, devido à complexidade do tema escolhido, o que incentivou a buscar informações relacionadas ao tema em sites internacionais, que tivesse o cálculo que melhor se adaptasse ao empreendimento. Para melhor entendimento fez-se necessário realizar este cálculo do hag. per capita para adequar ao faturamento da organização.

O Segundo objetivo da pesquisa teve como finalidade verificar o Holiday Footprint Method - HFM da demanda potencial e as estratégias mercadológicas gerando um diferencial competitivo ao empreendimento. No qual pode-se perceber um perfil peculiar dos entrevistados, relacionado ao pagamento e interesse em contribuir com o meio ambiente. A grande maioria dos entrevistados possui o desejo de minimizar o seu passivo ambiental, 


\section{ayplied towinger}

Volume 2, número 1,2017, p. 176-200

porém a pesquisa apresentou dados, que o valor para a compensação é maior do que essa demanda pretende pagar.

Como neste método do Holiday o principal desencadeador é o deslocamento, o hotel ficará responsável em minimizar o impacto de suas atividades, devido a sua condição financeira, sugerindo que as empresas de transportes adotem as mesmas praticas para compensar os impactos causados por suas atividades. Cabe ressaltar o caráter de aplicabilidade da fórmula do EFM já ajustada ao ecossistema local (ou adaptar aos demais ecossistemas por hag e número de árvores plantadas) como indicador de compensação ambiental aos meios de hospedagem.

Frente os resultados, destaca-se como limite da pesquisa, ineditismo e a complexidade dos cálculos do tema para setor hoteleiro. Justifica-se esta afirmativa, pois a demanda real de clientes do hotel, a situação financeira relacionada aos preços praticados pelo empreendimento que não possibilitava grandes investimentos na proposta, sobretudo, a neutralização plena nos principais desencadeadores do passivo ambiental através do plantio de árvores pela ONGSOS Mata Atlântica.

Como todos os estudos encontrados somente abordam o cálculo da pegada ambiental para cidades e/ou no máximo indústrias, acredita-se que o estudo pleno desta temática, com a simplificação e demonstração de sua aplicabilidade no setor turístico, especificamente hotelaria, pode e deve contribuir com a evolução da ciência da administração e do setor turístico (agências, transportes, eventos entre outros), para tanto, mereceria maior tempo e disponibilidade para tal efetivação.

Sugere-se por fim, pesquisas futuras acerca do tema, e da organização estudada a fim de ampliar os conhecimentos nesta área em específico. 


\section{(6)

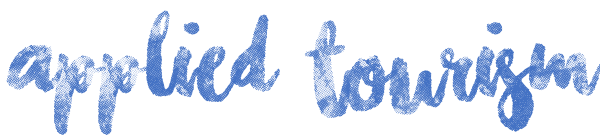

Volume 2, número 1,2017, p. 176-200

\section{REFERÊNCIAS}

ABEOC. (2014). Empresa inglesa conclui primeiro relatório ambiental da Copa de 2014. Disponível em: http//:www.abeoc.org.br. Acesso em: 25 abr. 2014.

Andrade, B. B. (2006). Turismo e sustentabilidade no município de Florianópolis: uma aplicação do método da Pegada Ecológica. 2006. 152f. Dissertação (Mestrado em Administração) Curso de Pós-Graduação em Administração, UFSC.

Andrade, D. F.; Tavares, H. R.; Valle, R. C. (2000). Teoria da resposta ao item: conceitose aplicações São Paulo: ABE - Associação Brasileira de Estatística.

Andrade, J. C. S., Costa, P. (2009). Mudança climática, Protocolo de Kyoto e mercado de créditos de carbono: desafios à governança ambiental global. Revista Organizações \& Sociedade, v. 15, n. 45 , art. 2, p. 29-45.

Barbetta, P. A. (2011). Estatística aplicada às ciências sociais. 7 ed. Florianópolis: Ed. da UFSC.

Cunha, L. (1997). Economia e Política do Turismo. 3 ed. Lisboa: Mcgrawhill.

Dencker, A. F. M. (2001). Métodose Técnicas de Pesquisa em Turismo. 5. Ed. São Paulo: Futura.

Dias, I. V. (2007). Estratégias de gestão de compra de energia elétrica para distribuidoras no Brasil. Curitiba.

Feitosa, M., Gómez, C. (2013). Aplicação do EFM para avaliação dos impactos ambientais do tunismo em ilhas: um estudo de Fernando de Noronha. Revista Brasileira dePesquisa em Turismo., v. 7, n. 2, p. 220-238.

Folha de São Paulo (2014). Copa do Mundo. Disponível em: www.folha.uol.com.br. Acesso em: 30 jun. 2014.

Forner, N. (2010). PegadaEcológica: Investimento da Simarsul na Contra Pegada do ano de 2008. Quercus.

Furtado,J. S., Hourneaux Junior, F., Hrdlicka, H. (2008). Avanços e percalços no cálculo da Pegada Ecológica Municipal: um estudo de caso. Revista de Gestão Sociale Ambiental, v. 2, n. 1, art. 5, p. 73-88.

Green Nation. (2014). Informações e aplicativos. Disponível em: http://www.greennation.com.br. Acesso em: 21 set. 2014.

Instituto Brasileiro de Meteorologia - INMET. (2014). Meteograma. Disponível em: http://www.inmet.gov.br. Acesso em: 21 set. 2014.

Instituto Brasileiro de Turismo - Embratur. (2014). Brasil é o $6^{\circ}$ no mundo em economia do turismo. Disponível em: http://www.embratur.gov.br. Acesso em: 25 abr. 2014.

Marconi, M., Lakatos, E. M. (1999). Técnicas de pesquisa. São Paulo: Atlas. 


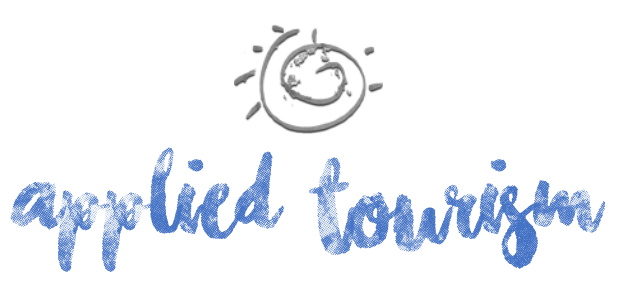

Volume 2, número 1,2017, p. 176-200

Ministério do Turismo. (2014). Portarias. Disponível em: http://www.turismo.gov.br/turismo/legislacao/portarias/20110621.html. Acesso em: 29 mar. 2014.

Ministry of Environment of Canada. (2013). B.C. Best Practices Methodology for Quantifying Greenbouse Gas Emissions: Including Guidance for Public Sector Organizations, Local Governments and Community Emissions. British Columbia. Disponível em: bttp://www2.gov.bc.ca. Acesso em: 27 ago. 2014.

Moura, L. A. R. (2008). O processo construção de paradigmas e migração da aprendizagem no âmbito da implementação da norma NBR ISO 14100, em meios de hospedagem. Dissertação de Mestrado (Eng. Da Produção) UFSC.

Neiman, Z., Rabinovici, A. (2010). Turismo e meio ambiente no Brasil. Barueri, SP.

Parente, A. (2007). Indicadores de sustentabilidade ambiental: Um estudo do Ecological Footprint Method do município de Joinville -SC, Dissertação de Mestrado - Universidade do Vale do Itajá.

Passaporte Verde. (2014). Estabelecimentos engajados. Disponível: em: http://www.passaporteverde.gov.br. Acesso em: 03 jun. 2014.

Quercus. (2014). Quercus e Sage Portugal disponibilizam calculadora online da Pegada Ecológica das Organizações. Disponível em: www.quercus.org.pt. Acesso em:21 set. 2014.

Roesch, S. M. A. (2011). Projeto de Estágio e de Pesquisa em Administração. 2. Ed. São Paulo: Atlas.

Sebastião, I. L. C. (2010). Aplicação da Pegada Ecológica ao Turismo. Como a Pegada Ecológica pode influenciar a Gestão Ambiental. Dissertação de Mestrado (Gestão e Políticas Ambientais) da Universidade Nova de Lisboa-Lisboa, 2010.

Sebrae. (2014). Gestão Ambiental. Disponível em: http//www.sebrae.com.br. Acesso em: 23 abr. 2014.

Secretaria Municipal de Turismo. (2014). Disponível em: www.pmfi.pr.gov.br. Acesso em: 12 mai. 2014.

Silva, L. M. T., Silva, M. P., Enders, W. T. (2012). Gestão ambiental e desempenho hoteleiro. Um estudo no Polo Costa das Dunas - RN. Revista Acadêmica do Observatório de Inovação do Turismo, v. 1, n. 3, p. 1-19.

SOS Mata Atlântica. (2014). Projeto Clickarvore. Disponível em: www.sosma.org.br. Acesso em: 04 ago. 2014.

Souza Filho, F. A. (2012). Recursos Naturais e Manejos, Ecossistemas e seus Usos. PBMC - Painel Brasileiro de Mudanças Climáticas. Primeiro relatório de avaliação nacional. Volume 2 Impactos, vulnerabilidades e adaptação. Disponível em: http://www.pbmc.coppe.ufrj.br/documentos/Nolume_2/GT2_RAN1_Draft_1_Cap4_Con sulta\%20pu\%CC\%81blica.pdf. Acesso em:30 mai. 2014. 